\title{
Impact of COVID-19 and Lockdown on Children with ADHD and Their Families-An Online Survey and a Continuity Care Model
}

\author{
Ruchita Shah $^{1}$ V. Venkatesh Raju ${ }^{1} \quad$ Akhilesh Sharma ${ }^{1} \quad$ Sandeep Grover ${ }^{1}$ \\ ${ }^{1}$ Department of Psychiatry, Post Graduate Institute of Medical \\ Address for correspondence Sandeep Grover, MD, Department of \\ Education and Research, Chandigarh, India \\ Psychiatry, Post Graduate Institute of Medical Education and Research, \\ Chandigarh, 160012, India (e-mail: drsandeepg2002@yahoo.com).
}

\begin{abstract}
Background Little is known about the impact of the coronavirus disease 2019 pandemic on children with attention-deficit hyperkinetic disorder (ADHD). This study aimed to assess the impact of lockdown on children with the ADHD, and their families. Additionally, feasibility of carrying out "text message-based" intervention was evaluated.

Methods An online survey was performed to evaluate the impact of lockdown on children with ADHD and their family members. Additionally, a "text message"-based intervention was performed over 2 weeks. Along with the text-based intervention, we also provided reading materials and an option of telephonic consultation.

Results Of the 80 parents who initially consented to participate, 48 filled the baseline survey, and 41 agreed to receive intervention. Out of 41,29 filled satisfaction survey. During the lockdown period, there was worsening of symptoms of ADHD in the form of increase (slight or marked) in the activity level (50.1\%), irritability (45.8\%), and disturbing or disruptive behavior (47.7\%) in children. In terms of behavior of family members, there was marked/slight increase in irritability (37.5\%), and shouting at the child (43.8\%), verbal abuse (25\%), and punishing the child (27.1\%). Additionally, there was an increase in the praising (67.6\%) and spending time with the child (72.9\%). Text-based messages on a scale of 0 to 10 were rated as 5.79 for the content, 5.76 for

Keywords

- ADHD

- survey

- text message

- intervention the usefulness, and 6 for satisfaction.

Conclusion Lockdown resulted in worsening of symptoms among children of ADHD and it had impact on the interaction pattern of the children and parents. A "text message"-based intervention is a feasible and possibly acceptable option to deal with the behavioral problem of the children and adolescents with ADHD.
\end{abstract}

\section{Key Messages}

- Lockdown led to worsening of symptoms in a significant proportion of children with attention-deficit hyperkinetic disorder (ADHD).

- It is feasible to carry out intervention by using text-based messages for parents of children with ADHD.

DOI https://doi.org/ 10.1055/s-0040-1718645 ISSN 0976-3147.

\section{Introduction}

Children with the attention-deficit hyperkinetic disorder (ADHD) suffer from inattention, hyperactivity, and impulsivity. These children usually move around rather than sitting still in one place, are not able to focus on one thing for long, disturb others in day to day communication. ${ }^{1}$ Due to their illness, they also have problems in carrying out tasks

(c) 2020. Association for Helping Neurosurgical Sick People.

This is an open access article published by Thieme under the terms of the Creative Commons Attribution-NonDerivative-NonCommercial-License, permitting copying and reproduction so long as the original work is given appropriate credit. Contents may not be used for commercial purposes, or adapted, remixed, transformed or built upon. (https://creativecommons.org/licenses/by-nc-nd/4.0/)

Thieme Medical and Scientific Publishers Pvt. Ltd., A-12, 2nd Floor, Sector 2, Noida-201301 UP, India 
to completion like schoolwork, homework, or any organizational tasks. ${ }^{1}$ The ADHD-related disruptive behaviors can also become a source of problem for the family. Managing these children in the home and school is often challenging. ${ }^{2}$ A qualitative study suggests that behavior of the child with ADHD is felt like a "wrecking ball"; and parents often feel like it is war at home, has negative impact on relationships, and parents find it difficult to work. Overall parents report high level of stress. $^{3}$

Coronavirus disease 2019 (COVID-19) pandemic led to complete lockdown in many countries, including India. All the schools were closed and classes were suspended, with some level of resumption of online classes in some of the schools. Due to lockdown, the children are expected to spend time inside the home. For children with ADHD, it is known that staying inside the home in a situation like a lockdown can be extremely difficult. ${ }^{4}$ They can become a constant source of disturbance to their family members and families can have problems in handling them. Making these children sit beyond a certain timeframe can lead to significant distress to these children. ${ }^{5}$ Further, allowing their hyperactivity to continue can lead to significant distress for the parents. ${ }^{5}$ Further, due to more free time, fewer outdoor activities, these children are more prone to indulge in the use of screen media. ${ }^{6}$ However, in this unprecedented situation of lockdown, it is not known how the children with ADHD and their parents are dealing with the child's hyperactivity. Usually, parents do not have time to carry out behavioral interventions for these children, due to their busy schedule, and work pressure. If one sees the lockdown from this perspective, it can be understood as an opportunity for the parents and family members to learn the principles of behavior therapy to manage these children more effectively. However, lockdown also led to the closure of health care services, and resultantly, parents, who were interested in learning and implementing the behavioral principles in handing their children with ADHD, did not have access to mental health care services. Management of ADHD involves the use of stimulants in a significant proportion of patients and nonavailability of the same can lead to worsening of the ADHD. ${ }^{7}$ The recently released telemedicine guidelines have kept prescription of stimulants out of the preview of the online prescriptions. ${ }^{8}$

In recent times, to overcome some of the problems encountered in providing behavioral interventions for children with ADHD, studies have evaluated the feasibility and acceptability of multipoint videoconferencing-based intervention for parents with ADHD and have shown that compared with to face-to-face consultations, videoconferencing is more cost and time-saving. However, the authors reported occasional problems with Internet connectivity and audio-video lag. ${ }^{9}$ However, this intervention required synchronous communication and dedicated time, which could be difficult for some of the parents. Studies from other parts of the world have evaluated SMS-based mobile interventions for parents of adolescents and suggest this to be an effective and feasible method to provide evidence-based information to parents, who cannot be easily reached. ${ }^{10}$ Keeping these issues in mind, this study was conceived to provide continuity of care and also to utilize the availability of parents at home to improve the outcome of the children with ADHD.

In this background, this pilot study was conceptualized to understand the behavioral issues of the children with ADHD and provide simple "text message"-based intervention for the parents. Accordingly, this study aimed to carry out an online survey to assess the problems faced by children with ADHD and their families in terms of managing the child and various other practical difficulties like buying medications such as stimulants that have various restrictions making it difficult for the families to avail treatment. Additionally, it was aimed to provide a "text message-based" intervention and option of telephonic consultation for the parents of children with ADHD to assess their satisfaction with the same.

\section{Methods}

For this study, an online questionnaire was designed to assess the behavior of the children with ADHD and their parents during the ongoing lockdown period. Certain items (items that were considered irrelevant in the context of lockdown were left out) were taken from the Vanderbilt ADHD parent rating scale to assess the severity of ADHD. ${ }^{11}$ Families of children diagnosed with ADHD, registered with Child and Adolescent Psychiatry (CAP) Clinic, of the institute, who were actively following up before the lockdown, were initially contacted over phone. The contact details were extracted from the available treatment records. The well-being of the patient and the family was enquired and they were informed about the study. Those who agreed to participate were initially sent a text message, providing information about the survey. They were again asked about their willingness to participate and those who wanted to continue further were asked to respond by saying "yes." Accordingly, this was a closed survey, which was sent to a select group of parents who were directly approached by the research team. The whole questionnaire was presented as a single-page survey by using Survey Monkey Platform. The data as collected in the Survey Monkey Platform could be assessed by only one of the investigators. Only the research team had access to the personal information of the participants and at the time of analysis of data, personal identification data was removed. No incentive was offered to the participants. Whenever physical abuse was reported, it was handled keeping with international best practice in ethics.

Those who responded to the initial message with "yes" were sent a link for the online survey. After successful submission of the survey, a second invitation was sent seeking permission, whether they would like to receive messages through WhatsApp messenger for improving the child's behavior. For those responding with "yes," a brief intervention was performed for the next 2 weeks over WhatsApp messenger. At the end of 2 weeks, again an invitation was sent over WhatsApp messenger to refill the outcome survey.

In addition to this, all the families were told that they can call the treating team on any day between 12 noon and $1 \mathrm{pm}$ if they need to discuss any issues related to child symptoms, 
irrespective of their participation in the survey. The study was approved by the ethics committee of the institute.

The online "text-based" intervention included six messages delivered for 2 weeks at a frequency of three messages per week. The messages covered areas of identifying and managing problematic behaviors of the child during the lockdown, use of contingency management with the child, positive parenting principles like consistency, effective communication skills like cutting down critical comments and use of clear and concise instructions, time out strategies, how to handle excess screen use, and how to enhance effective and supervised screen use. ${ }^{12}$ In addition to these, a UNICEF manual for parents and caregivers titled "Psychosocial support for the children during COVID-19" was also circulated along with the second message. ${ }^{13}$

\section{Results}

As per the available records, we had telephone contact details of at least one family member of 137 children with ADHD. These family members were the accompanying persons, who accompanied the children to the outpatient services or had participated in at least one session of one of the online or offline groups psychoeducation program on ADHD run by the CAP services. Out of these, 19 could not be contacted and among those contacted, 38 did not consent to participate in the online survey and the intervention. Resultantly, at first level, the message for consent was sent to 80 family members, of whom 48 filled the survey, and 32 did not fill the survey. Among those who filled the survey, 36 consented to receive the "text message"-based intervention and among those who did not agree to fill the survey, 5 were interested in receiving the "text message"-based intervention. Accordingly, 41 families received the intervention, of which 29 filled the follow-up survey ( - Fig. 1 ).

Among the 48 participants, who completed the initial survey, nearly equal proportions of participants were fathers (47.9\%) and mother (45.8\%) of the child. A small proportion of them were other relatives (6.3\%).

The mean age of the children with ADHD was 9.79 (standard deviation 3.72) years. The majority of the participants was male (89.6\%). The mean number of children,

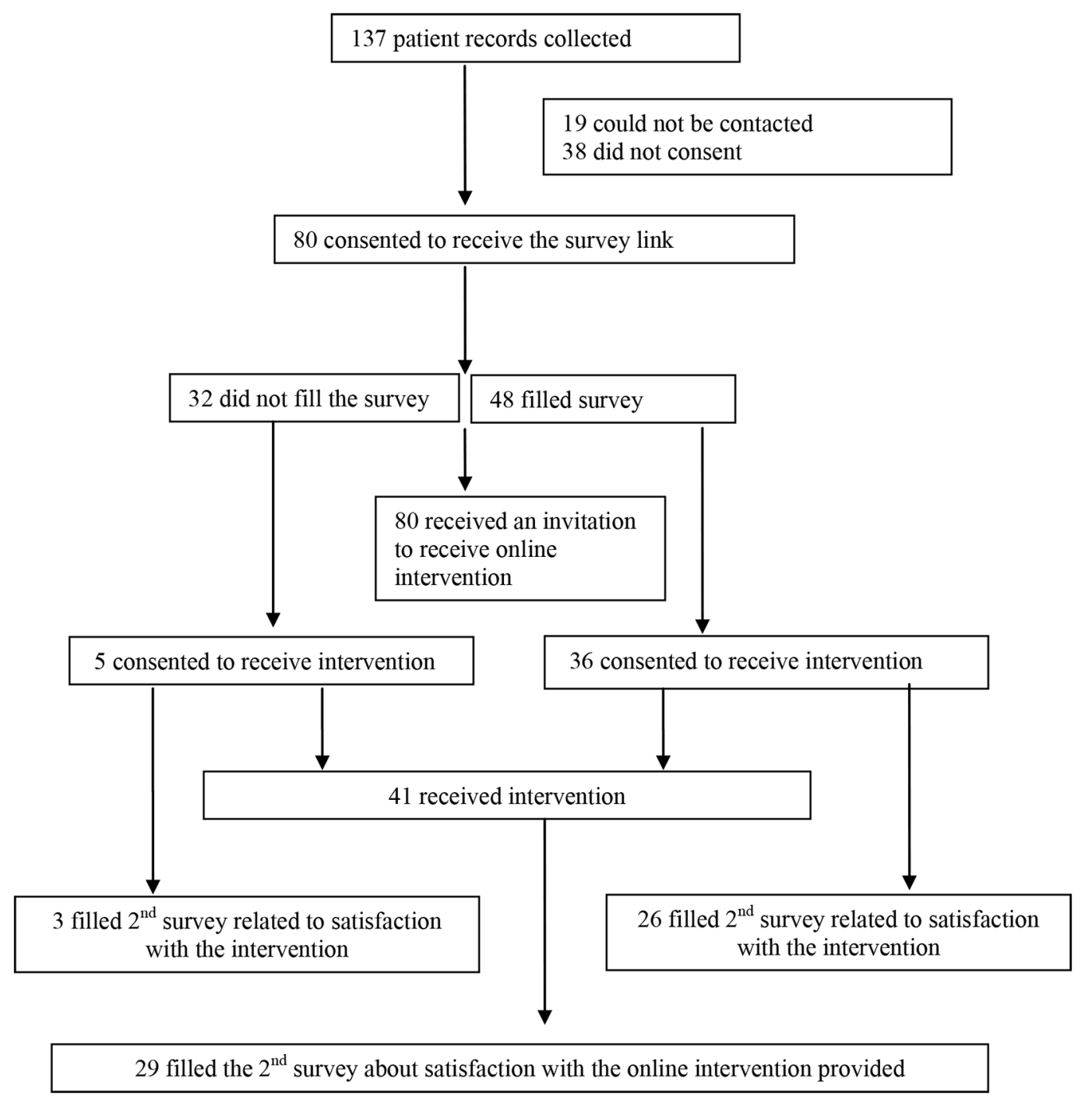

Fig. 1 Flow of participants in the different stages of the study 
including the child diagnosed with ADHD in the household, was $1.71(0.58)$. Nearly half $(45.8 \%)$ of the parents were not going to work due to the lockdown or were homemakers. During the study period, six parents sought telephonic help at the specified time of the day.

As is evident from - Table 1, about half of the children had worsening of ADHD symptoms in the form of increase (slight or marked) in the activity level (50.1\%), irritability (45.8\%), and disturbing or disruptive behavior (47.9\%). Further, there was an increase in screen media use in about half of the children, in the form of an increase in watching TV (48\%), playing games on mobile ( $54.2 \%)$, and use of mobile (56.3\%). About one-quarter to one-third of children also had an increase in anxiety (29.1\%), feeling of boredom (35.4\%), demanded more time from the parents (35.5\%), and were distressed for not being able to go out of the home (39.6\%). In terms of positive outcomes of lockdown, there was an increase in time spent in studying in about half of the children (37.5\%), and in slightly more than half of the children, there was an increase in helping parents in the household work (56.3\%) and slightly less than half indulged in creative activities (43.8\%).

In terms of other positive aspects of lockdown, there was an increase in the performance of studies, that is, reading, writing, and mathematics in more than one-third of the children. Additionally, there was an improvement in the relationship with parents, siblings, peers, and participation in organized activities in about one-fourth to one-third of the children (-Table 2).

About half of the children had been prescribed the medications ( $n=26 ; 52 \%$ ), before the lockdown. However, due to lockdown, more than half of the parents reported difficulty in purchasing the medications and overall $84.6 \%$ were continuing with the medications. Those parents who reported the need for fresh prescription to procure the medications, the same was facilitated through the emergency services. In terms of behavioral strategies (punishment, reward, particular schedule) being followed, as recommended earlier, half of the parents were able to follow the same to some extent (54.2\%), $6.3 \%$ were able to follow the same to great extent, and $14.6 \%$ were following the same completely.

In terms of parental behavior, there was a marked increase in time spent with the child by one-third (33.3\%) of parents. Further, there was an increase in praising the child by the parents. However, there was an increase in irritability, shouting at the child, hitting the child, verbal abuse, and punishing the child by a proportion of parents who completed the

Table 1 Impact of lockdown on children with ADHD

\begin{tabular}{|c|c|c|c|c|c|c|}
\hline Variables & $\begin{array}{l}\text { Markedly } \\
\text { increased } \\
n(\%)\end{array}$ & $\begin{array}{l}\text { Slightly } \\
\text { increased } \\
n(\%)\end{array}$ & $\begin{array}{l}\text { No } \\
\text { change } \\
n(\%)\end{array}$ & $\begin{array}{l}\text { Slightly } \\
\text { decreased } \\
n(\%)\end{array}$ & $\begin{array}{l}\text { Markedly } \\
\text { decreased } \\
n(\%)\end{array}$ & $\begin{array}{l}\text { Missing } \\
\text { information } \\
n(\%)\end{array}$ \\
\hline Activity level & $9(18.8)$ & $15(31.3)$ & $21(43.8)$ & $2(4.2)$ & - & $1(2.1)$ \\
\hline Watching TV & $8(16.7)$ & $15(31.3)$ & $18(37.5)$ & $6(12.5)$ & - & $1(2.1)$ \\
\hline Playing games on mobile & $12(25)$ & $14(29.2)$ & $12(25)$ & $5(10.4)$ & $4(8.3)$ & $1(2.1)$ \\
\hline Using the mobile & $14(29.2)$ & $13(27.1)$ & $12(25)$ & $7(14.6)$ & $1(2.1)$ & $1(2.1)$ \\
\hline $\begin{array}{l}\text { Playing video games on } \\
\text { other screen media }\end{array}$ & $4(8.3)$ & $5(10.4)$ & $27(56.3)$ & $4(8.3)$ & $7(14.6)$ & $1(2.1)$ \\
\hline Playing indoor games & $10(20.8)$ & $17(35.4)$ & $16(33.3)$ & $2(4.2)$ & $2(4.2)$ & $1(2.1)$ \\
\hline Studying & $5(10.4)$ & $13(27.1)$ & $19(39.6)$ & $4(8.3)$ & $6(12.5)$ & $1(2.1)$ \\
\hline Irritability/tantrums & $11(22.9)$ & $11(22.9)$ & $15(31.3)$ & $6(12.5)$ & $3(6.3)$ & $2(4.2)$ \\
\hline Anxiety & $4(8.3)$ & $10(20.8)$ & $24(50)$ & $5(10.4)$ & $2(4.2)$ & $3(6.3)$ \\
\hline Sleep & $5(10.4)$ & $10(20.8)$ & $21(43.8)$ & $8(16.7)$ & $2(4.2)$ & $2(4.2)$ \\
\hline Boredom & $6(12.5)$ & $11(22.9)$ & $21(43.8)$ & $5(10.4)$ & $1(2.1)$ & $4(8.3)$ \\
\hline $\begin{array}{l}\text { Disturbing or disruptive } \\
\text { behavior }\end{array}$ & $6(12.5)$ & $17(35.4)$ & $12(25)$ & $10(20.8)$ & $1(2.1)$ & $2(4.2)$ \\
\hline Demanding time from you & $3(6.3)$ & $14(29.2)$ & $21(43.8)$ & $6(12.5)$ & $1(2.1)$ & $3(6.3)$ \\
\hline $\begin{array}{l}\text { Talking to friends on the } \\
\text { phone }\end{array}$ & $2(4.2)$ & $4(8.3)$ & $29(60.4)$ & $5(10.4)$ & $5(10.4)$ & $3(6.3)$ \\
\hline $\begin{array}{l}\text { Talking to relatives on the } \\
\text { phone }\end{array}$ & $3(6.3)$ & $10(20.8)$ & $26(54.2)$ & $4(8.3)$ & $2(4.2)$ & $3(6.3)$ \\
\hline $\begin{array}{l}\text { Distress due to not able to } \\
\text { go out }\end{array}$ & $4(8.3)$ & $15(31.3)$ & $20(41.7)$ & $4(8.3)$ & $3(6.3)$ & $2(4.2)$ \\
\hline $\begin{array}{l}\text { Helping in household } \\
\text { chores }\end{array}$ & 7 (14.6) & $20(41.7)$ & $15(31.3)$ & $3(6.3)$ & $1(2.1)$ & $2(4.2)$ \\
\hline Creative activities & $6(12.5)$ & $15(31.3)$ & $23(47.9)$ & $1(2.1)$ & $1(2.1)$ & $2(4.2)$ \\
\hline
\end{tabular}

Abbreviation: ADHD, attention-deficit hyperkinetic disorder. 
survey. Overall, there was an increase in the praising and spending time with the child in more than half of the families. However, there was an increase in irritability (47.5\%), and shouting at the child (46.8\%), verbal abuse (25\%), and punishing the child $(27.1 \%)$ (-Table 3).

As shown in $\mathbf{- T a b l e} \mathbf{4}$, for all the symptoms, for more than half of children, the presence of symptoms was rated as often or very often in the previous 1 month. The severity of symptoms in various domains is shown in - Table $\mathbf{5}$.

Out of the 41 parents/families who had received the intervention, 29 responded to the satisfaction survey. As

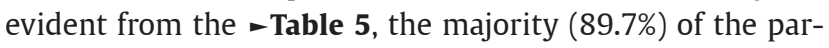
ents reported that they went through most of the messages, and the majority considered the messages to be of adequate length (96.6\%). When asked to rate the messages received in terms of content, usefulness, and satisfaction, the mean scores were $5.79,5.76$, and 6 , respectively (- Table 6). However, only half $(55.2 \%)$ of the parents considered the "text messages" to be useful in managing the child with ADHD in a better way. When asked about suggestions to improve the "text messages" package, the most common suggestion was to provide symptom and age-specific interventions, which could be individually focused, rather than the generic information. Other suggestions included the inclusion of audio-video interactive sessions, the inclusion of more activities, and more frequent information/sessions.

It was also seen that ratings of content, usefulness, and satisfaction did not have any significant correlation with severity of inattention symptom scores, hyperactivity symptom scores, oppositional and defiance symptom scores, conduct

Table 2 Impact of lockdown on education and relationships

\begin{tabular}{|l|l|l|l|l|l|}
\hline Variables & Like before & Improved & Worsened & Missing \\
\hline Performance & $23(47.9)$ & $17(35.4)$ & $7(14.6)$ & $1(2.1)$ \\
\hline Reading & $25(52.1)$ & $18(37.5)$ & $4(8.3)$ & $1(2.1)$ \\
\hline Writing & $25(52.1)$ & $20(41.7)$ & $3(6.3)$ & $1(2.1)$ \\
\hline Mathematics & $24(50)$ & $20(41.7)$ & $3(6.3)$ & $1(2.1)$ \\
\hline Relationships & $28(58.3)$ & $13(27.1)$ & $2(4.2)$ & $5(10.4)$ \\
\hline Relationship with parents & $30(62.5)$ & $13(27.1)$ & $1(2.1)$ & $4(8.3)$ \\
\hline Relationship with siblings & $25(52.1)$ & $19(39.6)$ & $1(2.1)$ & $3(6.3)$ \\
\hline Relationship with peers & & & \\
\hline Participation in organized activities
\end{tabular}

Table 3 Impact of lockdown on the behavior of parents toward the child with ADHD

\begin{tabular}{|c|c|c|c|c|c|c|}
\hline Variables & $\begin{array}{l}\text { Markedly } \\
\text { increased } \\
n(\%)\end{array}$ & $\begin{array}{l}\text { Slightly } \\
\text { increased } \\
n(\%)\end{array}$ & $\begin{array}{l}\text { No change } \\
n(\%)\end{array}$ & $\begin{array}{l}\text { Slightly } \\
\text { decreased } \\
n(\%)\end{array}$ & $\begin{array}{l}\text { Markedly } \\
\text { decreased } \\
n(\%)\end{array}$ & Missing \\
\hline \multicolumn{7}{|c|}{ The behavior of parent filling the survey } \\
\hline Praising the child & $6(12.5)$ & $25(52.1)$ & $12(25)$ & $2(4.2)$ & - & $3(6.3)$ \\
\hline $\begin{array}{l}\text { Spending time with } \\
\text { the child }\end{array}$ & $16(33.3)$ & $19(39.6)$ & $7(14.6)$ & $3(6.3)$ & - & $3(6.3)$ \\
\hline Irritability & $5(10.4)$ & $13(27.1)$ & $18(37.5)$ & $6(12.5)$ & $3(6.3)$ & $3(6.3)$ \\
\hline Shouting at the child & $6(12.5)$ & $15(31.3)$ & $12(25)$ & $7(14.6)$ & $5(10.4)$ & $3(6.3)$ \\
\hline Hitting the child & $2(4.2)$ & $9(18.8)$ & $21(43.8)$ & $7(14.6)$ & $6(12.5)$ & $3(6.3)$ \\
\hline Verbal abuse & $2(4.2)$ & $10(20.8)$ & $20(41.7)$ & $4(8.3)$ & $9(18.8)$ & $3(6.3)$ \\
\hline Punishing the child & $2(4.2)$ & $11(22.9)$ & $23(47.9)$ & $4(8.3)$ & $4(8.3)$ & $4(8.3)$ \\
\hline \multicolumn{7}{|c|}{ The behavior of other family members in the house } \\
\hline Praising the child & $6(12.5)$ & $18(37.5)$ & $15(31.3)$ & $3(6.3)$ & $1(2.1)$ & $5(10.4)$ \\
\hline $\begin{array}{l}\text { Spending time with } \\
\text { the child }\end{array}$ & $10(20.8)$ & $21(43.8)$ & $10(20.8)$ & $1(2.1)$ & $2(4.2)$ & $4(8.3)$ \\
\hline Irritability & $2(4.2)$ & $10(20.8)$ & $21(43.8)$ & $7(14.6)$ & $3(6.3)$ & $5(10.4)$ \\
\hline Shouting at the child & $2(4.2)$ & $12(25)$ & $22(45.8)$ & $5(10.4)$ & $2(4.2)$ & $5(10.4)$ \\
\hline Hitting the child & $1(2.1)$ & $5(10.4)$ & $28(58.3)$ & $2(4.2)$ & $8(16.7)$ & $4(8.3)$ \\
\hline Verbal abuse & $1(2.1)$ & $4(8.3)$ & $26(54.2)$ & $4(8.3)$ & $8(16.7)$ & $5(10.4)$ \\
\hline Punishing the child & $1(2.1)$ & $5(10.4)$ & $25(52.1)$ & $6(12.5)$ & $6(12.5)$ & $5(10.4)$ \\
\hline
\end{tabular}

Abbreviation: ADHD, attention-deficit hyperkinetic disorder. 
Table 4 Severity of symptoms of ADHD as assessed by modified Vanderbilt ADHD severity scale

\begin{tabular}{|c|c|c|c|c|c|}
\hline Variables & $\begin{array}{l}\text { Never } \\
n(\%)\end{array}$ & $\begin{array}{l}\text { Occasionally } \\
n(\%)\end{array}$ & $\begin{array}{l}\text { Often } \\
n(\%)\end{array}$ & $\begin{array}{l}\text { Very } \\
\text { often } \\
n(\%)\end{array}$ & $\begin{array}{l}\text { Missing } \\
n(\%)\end{array}$ \\
\hline $\begin{array}{l}\text { 1. Doesn't pay attention to details or } \\
\text { makes careless mistakes }\end{array}$ & $10(20.8)$ & $13(27.1)$ & $16(33.3)$ & $7(14.6)$ & $2(4.2)$ \\
\hline $\begin{array}{l}\text { 2. Has difficulty keeping attention to } \\
\text { what needs to be done }\end{array}$ & $11(22.9)$ & $15(31.3)$ & $11(22.9)$ & $7(14.6)$ & $4(8.3)$ \\
\hline $\begin{array}{l}\text { 3. Doesn't seem to listen when spoken } \\
\text { to directly }\end{array}$ & $11(22.9)$ & $23(47.9)$ & $6(12.5)$ & $5(10.4)$ & $3(6.3)$ \\
\hline $\begin{array}{l}\text { 4. Doesn't follow through when given } \\
\text { directions and fails to finish } \\
\text { activities }\end{array}$ & $12(25)$ & $17(35.4)$ & $11(22.9)$ & $4(8.3)$ & $4(8.3)$ \\
\hline $\begin{array}{l}\text { 5. Has difficulty organizing tasks and } \\
\text { activities }\end{array}$ & $12(25)$ & $19(39.6)$ & $9(18.8)$ & $4(8.3)$ & $4(8.3)$ \\
\hline $\begin{array}{l}\text { 6. Avoids tasks that require ongoing } \\
\text { mental effort }\end{array}$ & $10(20.8)$ & $14(29.2)$ & $14(29.2)$ & $6(12.5)$ & $4(8.3)$ \\
\hline $\begin{array}{l}\text { 7. Loses things necessary for tasks or } \\
\text { activity }\end{array}$ & $15(31.3)$ & $16(33.3)$ & $8(16.7)$ & $5(10.4)$ & $4(8.3)$ \\
\hline 8. Is easily distracted by noises & $4(8.3)$ & $11(22.9)$ & $21(43.8)$ & $8(16.7)$ & $4(8.3)$ \\
\hline 9. Is forgetful in daily activities & $11(22.9)$ & $18(37.5)$ & $9(18.8)$ & $6(12.5)$ & $4(8.3)$ \\
\hline 10. Fidgets & $6(12.5)$ & $14(29.2)$ & $12(25)$ & $11(22.9)$ & $5(10.4)$ \\
\hline 11. Leaves seat when required to & $7(14.6)$ & $17(35.4)$ & $8(16.7)$ & $9(18.8)$ & $7(14.6)$ \\
\hline 12. Runs or climbs too much & $9(18.8)$ & $15(31.3)$ & $9(18.8)$ & $9(18.8)$ & $6(12.5)$ \\
\hline $\begin{array}{l}\text { 13. Has difficulty playing or beginning } \\
\text { quite play activities }\end{array}$ & $16(33.3)$ & $11(22.9)$ & $9(18.8)$ & $6(12.5)$ & $6(12.5)$ \\
\hline 14. On the go or as if driven by a motor & $15(31.3)$ & $11(22.9)$ & $11(22.9)$ & $4(8.3)$ & $7(14.6)$ \\
\hline 15. Talks too much & $7(14.6)$ & $13(27.1)$ & $13(27.1)$ & $11(22.9)$ & $4(8.3)$ \\
\hline 16. Blurts out answers & $13(27.1)$ & $12(25)$ & $13(27.1)$ & $5(10.4)$ & $5(10.4)$ \\
\hline 17. Difficulty waiting for turns & $6(12.5)$ & $13(27.1)$ & $16(33.3)$ & $9(18.8)$ & $4(8.3)$ \\
\hline 18. Interrupts or intrudes & $7(14.6)$ & $14(29.2)$ & $12(25)$ & $8(16.7)$ & $7(14.6)$ \\
\hline 19. Argues with adults & $10(20.8)$ & $13(27.1)$ & $12(25)$ & $7(14.6)$ & $6(12.5)$ \\
\hline 20. Loses temper & $5(10.4)$ & $17(35.4)$ & $11(22.9)$ & $9(18.8)$ & $6(12.5)$ \\
\hline 21. Actively defies & $6(12.5)$ & 19(39.6) & $12(25)$ & $5(10.4)$ & $8(12.5)$ \\
\hline 22. Deliberately annoys people & $14(29.2)$ & $14(29.2)$ & $8(16.7)$ & $4(8.3)$ & $8(16.7)$ \\
\hline 23. Blames others for his mistakes & $11(22.9)$ & $14(29.2)$ & $13(27.1)$ & $4(8.3)$ & $6(12.5)$ \\
\hline 24. Is touchy & $10(20.8)$ & $13(27.1)$ & $12(25)$ & $8(16.7)$ & $5(10.4)$ \\
\hline 25. Is angry and resentful & $6(12.5)$ & $20(41.7)$ & $10(20.8)$ & $7(14.6)$ & $5(10.4)$ \\
\hline 26. Is spiteful & $8(16.7)$ & $15(31.3)$ & $13(27.1)$ & $3(6.3)$ & $9(18.8)$ \\
\hline 27. Bullies, threatens & $16(33.3)$ & $11(22.9)$ & $11(22.9)$ & $3(6.3)$ & $7(14.6)$ \\
\hline 28. Starts physical fights & $12(25)$ & 15(31.3) & 11(22.9) & $4(8.3)$ & $6(12.5)$ \\
\hline 29. Lies to get out of trouble & $12(25)$ & $16(33.3)$ & $9(18.8)$ & $6(12.5)$ & $5(10.4)$ \\
\hline 30. Is physically cruel & $25(52.1)$ & $8(16.7)$ & $6(12.5)$ & $4(8.3)$ & $5(10.4)$ \\
\hline 31. Has stolen things & $28(58.3)$ & $10(20.8)$ & $3(6.3)$ & $2(4.2)$ & $5(10.4)$ \\
\hline 32. Has used weapon & $32(66.7)$ & $6(12.5)$ & $3(6.3)$ & $1(2.1)$ & $6(12.5)$ \\
\hline 33. Deliberate fire setting & $33(68.8)$ & $5(10.4)$ & $2(4.2)$ & $2(4.2)$ & $6(12.5)$ \\
\hline 34. Has broken into someone's home car & $33(68.8)$ & $5(10.4)$ & $1(2.1)$ & $1(2.1)$ & $8(16.7)$ \\
\hline 35. Is fearful, anxious, worried & $16(33.3)$ & $16(33.3)$ & $5(10.4)$ & $6(12.5)$ & $5(10.4)$ \\
\hline 36. If afraid to try new things & $15(33.3)$ & $9(18.8)$ & $14(29.2)$ & $4(8.3)$ & $5(10.4)$ \\
\hline 37. Feels worthless & $16(33.3)$ & $13(27.1)$ & $6(12.5)$ & $5(10.4)$ & $8(16.7)$ \\
\hline
\end{tabular}


Table 4 (Continued)

\begin{tabular}{|l|l|l|l|l|l|}
\hline Variables & $\begin{array}{l}\text { Never } \\
n(\%)\end{array}$ & $\begin{array}{l}\text { Occasionally } \\
\boldsymbol{n}(\%)\end{array}$ & $\begin{array}{l}\text { Often } \\
\boldsymbol{n}(\%)\end{array}$ & $\begin{array}{l}\text { Very } \\
\text { often } \\
\boldsymbol{n}(\%)\end{array}$ & $\begin{array}{l}\text { Missing } \\
\boldsymbol{n}(\%)\end{array}$ \\
\hline 38. Blames selzf & $26(54.2)$ & $11(22.9)$ & $4(8.3)$ & $2(4.2)$ & $5(10.4)$ \\
\hline 39. Feels lonely, unwanted & $19(39.6)$ & $13(27.1)$ & $5(10.4)$ & $5(10.4)$ & $6(12.5)$ \\
\hline 40. Is sad unhappy & $20(41.7)$ & $12(25)$ & $5(10.4)$ & $4(8.3)$ & $7(14.6)$ \\
\hline 41. Is self-conscious, easily embarrassed & $15(31.3)$ & $15(31.3)$ & $11(22.9)$ & $1(2.1)$ & $6(12.5)$ \\
\hline
\end{tabular}

Abbreviation: ADHD, attention-deficit hyperkinetic disorder.

Table 5 Severity scores after missing values were replaced as option "never" or score zero

\begin{tabular}{|l|l|l|}
\hline $\begin{array}{l}\text { Symptom } \\
\text { domains as } \\
\text { taken from } \\
\text { VADPRS }\end{array}$ & $\begin{array}{l}\text { Total score } \\
\text { Mean (SD) } \\
\text { (range) }\end{array}$ & $\begin{array}{l}\text { Average score } \\
\text { Mean (SD) (range) }\end{array}$ \\
\hline $\begin{array}{l}\text { Inattention prob- } \\
\text { lems (items 1-9) }\end{array}$ & $10.67(6.57)(0-25)$ & $1.19(0.73)(0-2.78)$ \\
\hline $\begin{array}{l}\text { Hyperactivity } \\
\text { problems } \\
\text { (items 10-18) }\end{array}$ & $11.29(7.33)(0-27)$ & $1.25(0.81)(0-3)$ \\
\hline $\begin{array}{l}\text { Oppositional } \\
\text { defiance problems } \\
\text { (items 19-26) }\end{array}$ & $9.25(5.91)(0-20)$ & $1.16(0.74)(0-2.5)$ \\
\hline $\begin{array}{l}\text { Conduct problems } \\
\text { (items 27-34) }\end{array}$ & $4.94(5.10)(0-18)$ & $0.62(0.64)(0-2.5)$ \\
\hline $\begin{array}{l}\text { Internalizing prob- } \\
\text { lems (35-41) }\end{array}$ & $5.62(5.08)(0-18)$ & $\begin{array}{l}0.80 \\
(0.725)(0-2.57)\end{array}$ \\
\hline Total score & $\begin{array}{l}41.87 \\
(26.56)(0-100)\end{array}$ & $\begin{array}{l}1.0213 \\
(0.65)(0-2.44)\end{array}$ \\
\hline
\end{tabular}

Abbreviations: Vanderbilt ADHD parent rating scale; SD, standard deviation.

problem symptom scores, internalizing problem symptom score, and total problem score.

\section{Discussion}

To the best of our knowledge, this is the first study, which focused on children of ADHD and their parents to evaluate the impact of COVID-19 and performed an online intervention. This survey aimed to evaluate the problems faced by children with ADHD and their families during the lockdown period and additionally aimed to provide a "text message-based" intervention and an option of telephonic consultation for the parents of children with ADHD and to evaluate their satisfaction with the same. The present survey shows that lockdown was associated with worsening of ADHD symptoms in the form of increase (slight or marked) in the activity level, irritability, and disturbing or disruptive behavior in half of the children. Additionally, in a major proportion of the children, the symptoms persisted as such and only a few children showed some improvement in the behavioral issues during the lockdown period. These findings are understandable considering the nature of the disorder and the restrictions imposed as part of the lockdown. This suggests that there is
Table 6 Satisfaction with the intervention provided for parents of children with ADHD

\begin{tabular}{|c|c|}
\hline Items & $\begin{array}{l}n=29 \\
\text { Mean (SD)/ } \\
\text { Frequency (\%) }\end{array}$ \\
\hline $\begin{array}{l}\text { Did you go through most of the messages } \\
\text { sent at regular intervals?-Yes }\end{array}$ & $26(89.7)$ \\
\hline \multicolumn{2}{|l|}{$\begin{array}{l}\text { How would you rate the length of informa- } \\
\text { tion provided every time? }\end{array}$} \\
\hline Adequate & $28(96.6)$ \\
\hline Too short & $1(3.4)$ \\
\hline $\begin{array}{l}\text { How would you rate the content of the infor- } \\
\text { mation provided on } 1-10 \text { ? }\end{array}$ & $\begin{array}{l}5.79(2.94) \\
\text { median: } 6\end{array}$ \\
\hline $\begin{array}{l}\text { How would you rate the usefulness of the } \\
\text { content on } 1-10 ?\end{array}$ & $\begin{array}{l}5.76(2.52) \\
\text { median: } 6\end{array}$ \\
\hline $\begin{array}{l}\text { How much are you satisfied with the kind of } \\
\text { information provided on } 1-10 \text { ? }\end{array}$ & $\begin{array}{l}6(2.73) ; \\
\text { median: } 7\end{array}$ \\
\hline \multicolumn{2}{|l|}{$\begin{array}{l}\text { Did the content help you in managing the } \\
\text { child in a better way? }\end{array}$} \\
\hline Yes & $16(55.2)$ \\
\hline Can’t say & $9(31)$ \\
\hline No & $4(13.8)$ \\
\hline \multicolumn{2}{|l|}{ Suggestions } \\
\hline Nil & $18(62)$ \\
\hline $\begin{array}{l}\text { Symptom and age-specific (individualized } \\
\text { sessions) }\end{array}$ & $5(17)$ \\
\hline More mobile and screen use & $1(3.4)$ \\
\hline Want more activities & $1(3.4)$ \\
\hline Want audio, video, and interactive sessions & $2(6.9)$ \\
\hline More frequent sessions & $1(3.4)$ \\
\hline Needs improvement & $1(3.4)$ \\
\hline
\end{tabular}

Abbreviations: ADHD, attention-deficit hyperkinetic disorder; SD, standard deviation.

a need for home-based interventions for these children to reduce their distress and that of their family members. Based on these findings, it can be said that the interventions need to focus on channelizing the high energy levels of the children in more productive indoor activities, addressing emotional disturbances (such as irritability, anxiety, and boredom), disruptive behaviors, and reducing the time of screen media use. Based on these inputs, we planned our intervention and included strategies such as token economy, contingency 
management, effective communication skills, time out activity scheduling to channelize the energy, and supervised and controlled screen use as part of the "text messages." Findings of this study also suggest that in the future, if such exigencies continue or any new exigency arises, the usual psychoeducation about the disorder needs to focus on some of these issues, to prepare the parents for handling their children.

The present study also suggests that lockdown was associated with certain positive outcomes, such as an increase in time spent in studying in about half of the children and slightly more than half of the children there was an increase in helping parents in the household work and slightly less than half indulged in creative activities. Implementation of these strategies reflects engaging the children in productive behavior and suggests that the same can be included as part of the interventions in the future. In terms of other positive aspects of lockdown, there was an increase in the performance of studies, that is, reading, writing, and mathematics in more than one-third of the children. Additionally, there was an improvement in the relationship with parents, siblings, peers, and participation in organized activities in about one-fourth to one-third of the children. The time spent by the parents with their children increased and similarly there was an increase in the use of praise by the parents. These findings possibly reflect the reduction in pressure of performance and availability of time with the parents to supervise the children and work on the relationship with their children, when they were relatively free. These findings possibly reflect the importance of having quality time with the children, especially those with ADHD.

However, there was also an increase in negative emotions and problematic behaviors in parents, such as irritability, shouting at the child, hitting the child, verbal abuse, and punishing the child in a proportion of the parents/ families. These findings possibly reflect the nature of the disorder, that is, when parents spend more time with these children, they can get exhausted and react adversely to their children. Accordingly, it is important to provide psychoeducation to the parents, in the form of taking turns in handling the children with ADHD and themselves should take a break or timeout to manage their own emotions and behaviors.

Many families reported difficulty in procuring the medications, especially stimulants. These difficulties can be understood from the perspective of inclusion of these medications in the category of schedule " $\mathrm{X}$ " and prohibited medications as per the telemedicine guidelines as issued by the government of India. ${ }^{8}$ Considering the importance of the use of these medications, the telemedicine guidelines should be suitably modified, so that stimulants can be judiciously prescribed to these children, especially in a lockdown situation, which in itself can lead to worsening of the symptoms.

The present study also reflects the feasibility of carrying out the "text-based" online intervention for families with ADHD. Along with the text-based intervention, we also provided reading materials and an option of telephonic consultation to the parents. Accordingly, it can be said that in the prevailing ongoing pandemic, our intervention provides information about feasibility of an alternative treatment model, which can be used in the absence of the routine outpatient services or can be used as an adjunct to the routine outpatient services, when there are available. Additionally, this survey reflects a reasonable level of satisfaction of the parents/family members with the same. Considering the feasibility and the level of satisfaction of the parents/ families, it can be said that there is a need to develop a more structured multimodality intervention, which could include text messages, and audio-video clips, to improve the usefulness of this kind of interventions and the satisfaction of the parents/families with the same.

\section{Limitations}

The findings of this study must be interpreted in light of its limitations. First the study sample was small; the study sample of children with ADHD was heterogeneous in terms of age groups, and the duration of intervention and implementation of the same was short. The outcome of the intervention was not evaluated by using any specific scale. The study should not be interpreted as an effectiveness study, rather it should be looked at as a feasibility study in terms of providing "text message"-based intervention. In terms of the impact of lockdown on the ADHD symptoms, we did not study other factors, such as family dynamics and other ongoing stressors, personality features of parents and other family members, all of which can influence the improvement or worsening of the ADHD symptoms. We did not carry out any interim analysis and did not contact back the families in case they reported worsening of symptoms. Rather we relied on the self-initiative of the parents. If this model is to be considered as an alternative model, then having provision for contacting back the families would improve the treatment model. We did not compare the demographic profile of parents who agreed to participate and who refused to participate, in the absence of the data for the later group. Future studies must try to overcome these limitations of the study.

\section{Conclusions}

To conclude, this study suggests that the lockdown situation has led to the worsening of symptoms in a significant proportion of children with ADHD, which requires clinical attention. Additionally, the lockdown has also led to expressions of certain negative emotions in the interaction between the children and the parents. However, there is also an improvement in certain other aspects of the interaction between parents and children with ADHD. The present study suggests that "text message"-based intervention is feasible and can be used to provide information and guidance to parents to deal with the behavioral problem of the children and adolescents with ADHD.

\section{Conflict of Interest}

None declared. 


\section{References}

1 Peasgood T, Bhardwaj A, Biggs K, et al. The impact of ADHD on the health and well-being of ADHD children and their siblings. Eur Child Adolesc Psychiatry 2016;25(11):1217-1231

2 Coghill D, Soutullo C, d'Aubuisson C, et al. Impact of attention-deficit/hyperactivity disorder on the patient and family: results from a European survey. Child Adolesc Psychiatry Ment Health 2008;2(1):31-35

3 Leitch S, Sciberras E, Post B, et al. Experience of stress in parents of children with ADHD: a qualitative study. Int J Qual Stud Health Well-being 2019;14(1):1690091

4 Casey KJ, Hagaman JL, Trout AL, et al. Children with ADHD in residential care. J Child Fam Stud 2008;17:909-927

5 Miranda A, Marco R, Grau D, Parenting stress in families of children with attention-deficit/hyperactivity disorder: the impact of ADHD subtype and oppositional defiant disorder comorbidity [Internet]. In: Scruggs TE, Mastropieri MA, eds. International Perspectives. Bingley, West Yorkshire, UK: Emerald Group Publishing Limited; 2007 [cited 2020 Jun 16]

6 Tandon PS, Sasser T, Gonzalez ES, Whitlock KB, Christakis DA, Stein MA. Physical activity, screen time, and sleep in children with ADHD. J Phys Act Health 2019;16(6):416-422

7 Felt BT, Biermann B, Christner JG, Kochhar P, Harrison RV. Diagnosis and management of ADHD in children. Am Fam Physician 2014;90(7):456-464
8 Telemedicine Practice Guidelines - Enabling Registered Medical Practitioners to Provide Healthcare Using Telemedicine. Published 25 March 2020. Available at: https://www.mohfw. gov.in/pdf/Telemedicine.pdf. Accessed on 21 May 2020

9 Shah R, Chakrabarti S, Sharma A, Grover S, Sachdeva D, Avasthi A. Participating from homes and offices: proof-ofconcept study of multi-point videoconferencing to deliver group parent training intervention for attention-deficit/ hyperactivity disorder. Asian J Psychiatr 2019;41:20-22

10 Chu JTW, Wadham A, Jiang Y, et al. Effect of MyTeen SMS-based mobile intervention for parents of adolescents: a randomized clinical trial. JAMA Netw Open 2019;2(9):e1911120

11 Wolraich ML, Lambert W, Doffing MA, Bickman L, Simmons T, Worley K. Psychometric properties of the vanderbilt ADHD diagnostic parent rating scale in a referred population. J Pediatr Psychol 2003; 28: 559-568.

12 Shah R, Sharma A, Grover S, et al. PGIMER Manual: Parent Training for Families of Children with Attention Deficit/ Hyperactivity Disorder. Chandigarh: Department of Psychiatry, Postgraduate Institute of Medical Education and Research; 2018

13 CHILDLINE and UNICEF India. Psychosocial support for children during COVID-19: A manual for parents and caregivers. Published April 2020. Available at: https://www.unicef.org/ india/reports/psychosocial-support-children-duringcovid-19. Accessed May 21, 2020 